\title{
Correlation between the foetal acid-base status and the Apgar score*
}

\author{
K. H. LEE $\dagger$ \\ M.D., M.R.C.O.G. \\ University of Hong Kong
}

\begin{abstract}
Summary
The foetal pH values of eighty-eight cases delivered within $\mathbf{3 0}$ min after foetal blood sampling were correlated with the 1-min Apgar score. With a pH of 7.20 or above the error of prediction was $1.3 \%$. The error in cases with pH below $7 \cdot 20$ was $54.5 \%$.

Significantly higher pH and lower $\Delta$ base deficit were present in the low foetal $\mathrm{pH}$ group in vigorous, as opposed to depressed infants, suggesting that infusion acidosis was present in infants with a high Apgar score.

The degree of correlation between the foetal $\mathrm{pH}$ and the Apgar score was not significantly influenced by shortening the sampling-delivery interval to $15 \mathrm{~min}$ or lengthening it to $3 \mathrm{hr}$. The most significant factor affecting the degree of correlation in the present study was the setting of the critical pH. If the criterion of the critical $\mathrm{pH}$ was taken as $7 \cdot 13$ there would have been no false positive results and the error of prediction in cases delivered within $30 \mathrm{~min}$ of foetal blood sampling would be reduced to $1 \cdot 1 \%$.
\end{abstract}

THE foetal $\mathrm{pH}$ has been regarded as the most valuable parameter for the diagnosis of foetal hypoxia and depressed foetal acid-base values have been shown to be closely correlated with the severity of foetal asphyxia (Saling, 1965; Beard, Morris \& Clayton, 1966). Correlation between the foetal $\mathrm{pH}$ and the Apgar score by previous workers has not given consistent results (Beard, Morris \& Clayton, 1967; Paul, Gare \& Whetham, 1967; Haworth, Milic \& Adamson, 1968; Hon, Khazin \& Paul, 1969; Lumley \& Wood, 1969; Galloway, 1970). This has been attributed by Beard (1970) to the fact that many workers have not taken the sampling-delivery interval into consideration. Hon et al. (1969) have also shown that big discrepancies between the $\mathrm{pH}$ and the Apgar score are due to the time interval between foetal blood sampling and delivery. Eeard and his coworkers (Beard et al., 1967) have studied only cases delivered within 30 min after foetal blood sampling and think that an interval of more than $30 \mathrm{~min}$ is too long. On the other hand Galloway (1970) has attained

\footnotetext{
* The material in this paper has been taken from an M.D. Thesis submitted to the University of Hong Kong.

† Present address: Tsan Yuk Hospital, Hospital Road, Hong Kong.
}

good correlation between $\mathrm{pH}$ and score in cases delivered within $3 \mathrm{hr}$ after sampling.

This paper presents the results of a study of the relationship between the foetal $\mathrm{pH}$ and the Apgar score at three different sampling-delivery intervals, namely $3 \mathrm{hr}, 30 \mathrm{~min}$ and $15 \mathrm{~min}$.

\section{Material and methods}

Foetal blood sampling was performed in 307 Chinese patients at the Tsan Yuk Hospital, Hong Kong from January 1969 to March 1970. Fifty-six of these were normal cases, 200 showed clinical signs of foetal distress and the remaining fifty-one were high risk cases. The details of the acid-base status of this series have been reported separately (Lee, 1972b). A total of 206 cases were delivered within $3 \mathrm{hr}$ after the last foetal blood sample was collected. The samplingdelivery interval was within $30 \mathrm{~min}$ in eighty-eight cases and within 15 min in forty-six.

The foetal $\mathrm{pH}$ values were divided between those above and below 7.20. The Apgar scores taken at 1 min after birth were divided between 6 and 7 to differentiate depressed from vigorous infants. The relationship between the foetal $\mathrm{pH}$ and the Apgar score was studied in a manner similar to that of Beard and his co-workers (Beard et al., 1967).

\section{Results}

\section{Sampling-delivery interval within $30 \mathrm{~min}$}

Figure 1 is a scattergram showing the foetal $\mathrm{pH}$ of the eighty-eight cases in relation to the Apgar score. The horizontal line divides the $\mathrm{pH}$ values above and below $7 \cdot 20$. The vertical line separates the vigorous from the depressed infants.

Group A consisted of seventy-six cases with foetal pH 7.20 or above and Apgar score of 7 or more. Group X contained five cases with pH below 7.20 and low Apgar score. These two groups represented correct predictions of the condition of the infant from the $\mathrm{pH}$ of the foetal blood sample. They comprised eighty-one of the eighty-eight cases or $92.1 \%$.

Group B contained only one case with normal pH but low score. Group Y was made up of six cases with low $\mathrm{pH}$ but vigorous infants. These seven cases were the erroneous predictions giving an error of $7.9 \%$. 


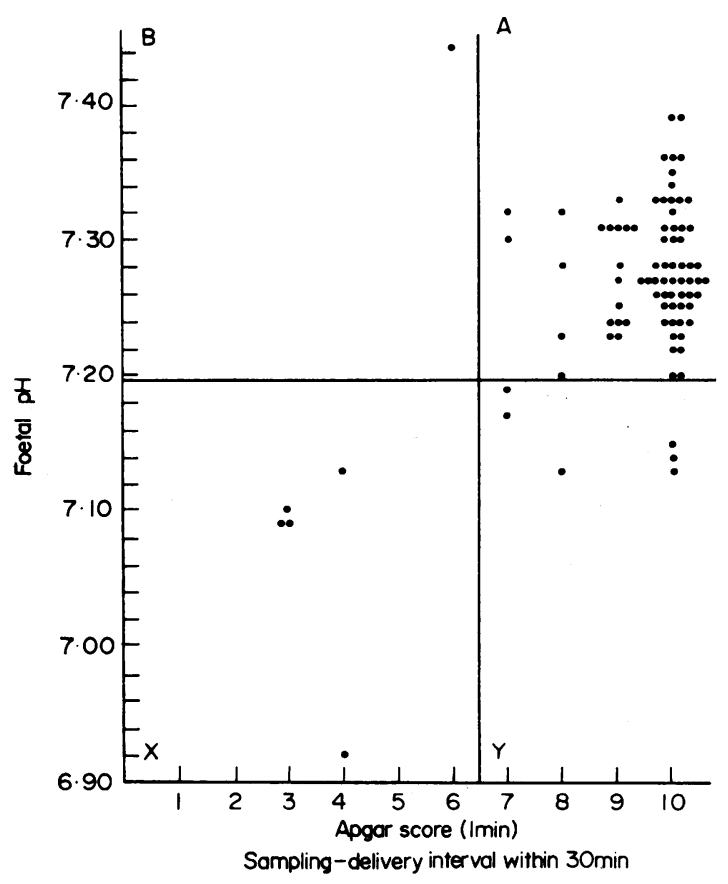

FIG. 1. Distribution of $\mathrm{pH}$ values relative to Apgar score in eighty-eight cases delivered within 30 min after foetal blood sampling.

The mean acid-base values for each of the groups $\mathrm{A}, \mathrm{X}$ and $\mathrm{Y}$ are shown in Table 1. The mean foetal $\mathrm{pH}$ in group $\mathrm{A}$ was $\mathbf{7 . 2 8}$ and the mean maternal $\mathrm{pH}$ 7·38. These values showed no significant difference from those found during normal labour in Chinese women as reported separately (Lee, 1972a).

The mean foetal $\mathrm{pH}$ in group $\mathrm{X}$ was 7.07. This, and the values of $\mathrm{pHqu} 40, \mathrm{PCO}_{2}$, standard bicarbonate, base deficit and $\triangle$ base deficit were all significantly different from those in group $\mathrm{A}(P<0.001)$. The mean maternal $\mathrm{pH}$ in group $\mathrm{X}$ was 7.36 which showed no significant difference from that in group $\mathrm{A}$.

Cases in group $\mathrm{Y}$ had a mean foetal $\mathrm{pH}$ of $7 \cdot 15$ which was significantly lower than that in group $\mathrm{A}$ $(P<0.001)$. Comparison between groups $\mathrm{X}$ and $\mathrm{Y}$ showed that the acidosis in group $X$ was more severe. The mean foetal $\mathrm{pH}, \mathrm{pHqu} 40$ and standard bicarbonate were significantly lower in group $\mathrm{X}$ and the mean base deficit and $\Delta$ base deficit were signific- antly higher. All the cases in group $\mathrm{Y}$ had a foetal $\mathrm{pH}$ of above $7 \cdot 13$ whereas it was below $7 \cdot 13$ in all the cases in group $X$. Furthermore, the $\Delta$ base deficit in group $X$ was more than $4 \mathrm{mEq} / 1$ in all cases whereas in group $Y$ it was less than $4 \mathrm{mEq} / 1$ in three of the five cases.

In the seventy-seven cases with $\mathrm{pH}$ above $7 \cdot 20$, the Apgar score was 7 or more in seventy-six $(98.7 \%)$. Only one infant $(1.3 \%)$ was depressed at birth. Of the other eleven cases with foetal $\mathrm{pH}$ less than $7 \cdot 20$, five $(45.5 \%)$ were depressed and six $(54.5 \%)$ recorded a score of 7 or more. The difference in the incidence of neonatal asphyxia between the group with high $\mathrm{pH}$ and that with low $\mathrm{pH}$ was highly significant $(P<0.001)$.

\section{Sampling-delivery interval within $15 \mathrm{~min}$}

Figure 2 shows the relationship between the foetal $\mathrm{pH}$ and Apgar score in the forty-six cases delivered within $15 \mathrm{~min}$ after foetal blood sampling. The error in prediction was $8.7 \%$ (four cases) which was not lower than that in cases with sampling-delivery interval within $30 \mathrm{~min}$.

\section{Sampling-delivery interval within $3 \mathrm{hr}$}

The distribution of the $\mathrm{pH}$ relative to the Apgar score in these 206 cases is shown in Fig. 3. The nineteen cases of erroneous predictions (groups and $\mathrm{Y}$ ) constituted an error of $9.2 \%$, which was not significantly different from the error in cases delivered within $\frac{1}{2} \mathrm{hr}$ of sampling. Among the cases with $\mathrm{pH}$ higher than 7.20 nine of the 192 infants were depressed at birth $(4 \cdot 7 \%)$. Of the fifteen infants with $\mathrm{pH}$ lower than $7 \cdot 20$, ten $(66.7 \%)$ had Apgar scores of 7 and above.

\section{Discussion}

Considering the cases delivered within $30 \mathrm{~min}$ after foetal blood sampling, the error in prediction in the present series was $7.9 \%$, which was lower than that of $18 \%$ reported by Bowe et al. (1970). Further study of the results showed that when the foetal pH was 7.20 or more, $98.7 \%$ of the infants were vigorous at birth. On the other hand, among the cases with foetal pH less than 7.20 only $45.5 \%$ were depressed at birth. Thus, the incidence of false negative results was only $1.3 \%$ while that of false positive results was $54.5 \%$.

TABLE 1. Mean acid-base values of groups $A, X$ and $Y$

\begin{tabular}{lccccrrr}
\hline & pH & pHqu40 & $\begin{array}{c}\text { Pco }_{2} \\
(\mathrm{mmHg})\end{array}$ & $\begin{array}{c}\text { Standard } \\
\text { bicarb. } \\
(\mathrm{mEq} / 1)\end{array}$ & $\begin{array}{c}\text { Base } \\
\text { deficit } \\
(\mathrm{mEq} / 1)\end{array}$ & $\begin{array}{c}\triangle \text { base } \\
\text { deficit } \\
(\mathrm{mEq} / 1)\end{array}$ & $\begin{array}{r}\text { Maternal } \\
\mathrm{pH}\end{array}$ \\
\hline Group A & $7 \cdot 28$ & $7 \cdot 33$ & $49 \cdot 9$ & $20 \cdot 5$ & $4 \cdot 7$ & $0 \cdot 1$ & $7 \cdot 38$ \\
Group X & $7 \cdot 07$ & $7 \cdot 13$ & $69 \cdot 3$ & $12 \cdot 7$ & 16.9 & $10 \cdot 1$ & $7 \cdot 36$ \\
Group Y & $7 \cdot 15$ & $7 \cdot 22$ & $54 \cdot 6$ & $15 \cdot 8$ & $11 \cdot 1$ & $4 \cdot 5$ & $7 \cdot 35$ \\
\hline
\end{tabular}




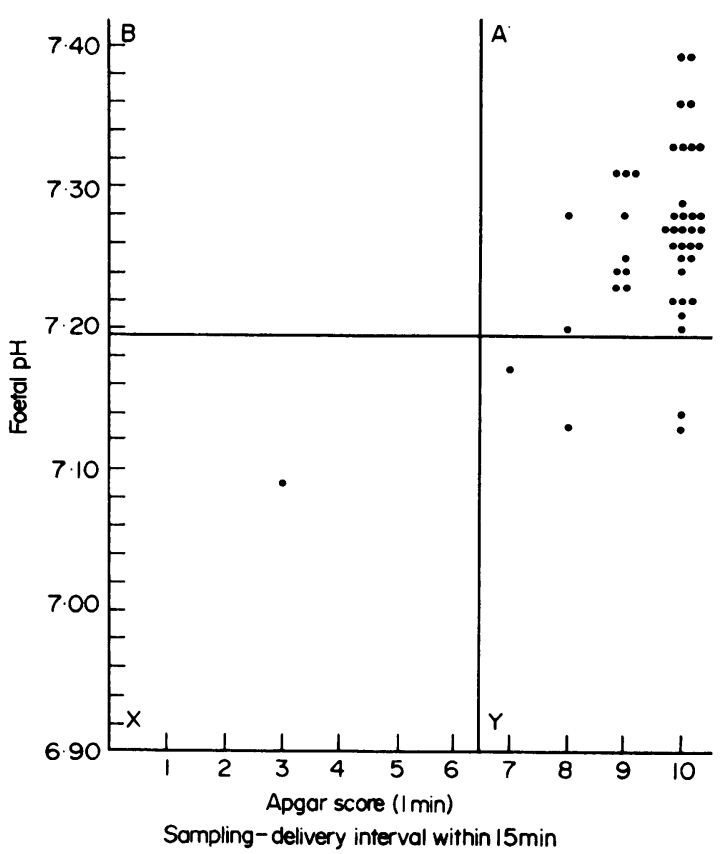

Fig. 2. Distribution of $\mathrm{pH}$ values relative to Apgar score in forty-six cases delivered within $15 \mathrm{~min}$ after foetal blood sampling.

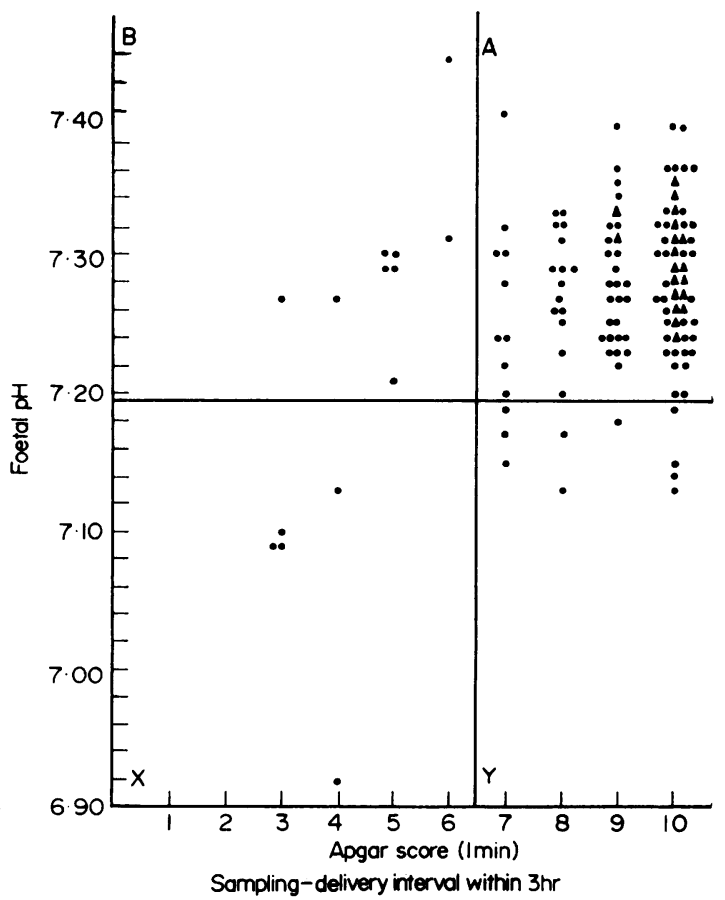

Fig. 3. Distribution of $\mathrm{pH}$ values relative to Apgar score in 206 cases delivered within $3 \mathrm{hr}$ after foetal blood sampling. $\Delta$ represents five points.
Other investigators have also encountered more false positive than false negative results and reported incidences have varied from 5 to $45 \%$ (Kubli, 1966; Paul, Gare \& Whetham, 1967; Wood et al., 1967). False negative results, that is normal $\mathrm{pH}$ and low score, are less acceptable. Beard (1970) suggested that the reason for the high incidences of false positive results obtained by some workers was that the sampling-delivery interval had not been taken into consideration.

Table 2 summarizes the results of three recent studies together with the present one in which foetal blood samples were collected within $30 \mathrm{~min}$ before delivery. In all these studies a foetal $\mathrm{pH}$ below 7.20 was considered abnormal and an Apgar score of less than 7 as evidence of a depressed infant. With normal foetal $\mathrm{pH}$ the infant was vigorous at birth in $87-98 \%$ of cases. However, a low foetal pH did not correlate so well with the condition of the infant at birth as a normal $\mathrm{pH}$. The incidences of false positive result in Table 2 ranged from 45 to $70 \%$. Beard et al. (1967) found twenty-five false positive cases out of a total of sixty acidotic foetuses and noted that the mean $\mathrm{pH}$ of this group was not as low as among the low Apgar score infants and that maternal acidosis was more common. They concluded that transient hypoxia and infusion acidosis were the major causes of false positive results.

Comparison between depressed and vigorous infants among those with low $\mathrm{pH}$ (group $\mathrm{X}$ and group $Y$ ) in the present series gave support to the view of Beard. The mean foetal $\mathrm{pH}$ of 7.07 among the depressed infants was significantly lower than that of $7 \cdot 15$ in cases with vigorous infants $(P<0.05)$. Furthermore, the $\Delta$ base deficit was significantly smaller in the infants with a high score indicating that a proportion of the acidotic foetuses in group $\mathrm{Y}$ were associated with a more pronounced maternal acidosis. Beard (1970) considers a $\Delta$ base deficit of less than $4 \mathrm{mEq} / 1$ as indicating infusion acidosis and a $\triangle$ base deficit of more than $4 \mathrm{mEq} / 1$ as meaning hypoxic acidosis. In the present cases, the $\Delta$ base deficit in group $X$ was more than $4 \mathrm{mEq} / 1$ in all cases whereas in group $Y$ it was less than $4 \mathrm{mEq} / 1$ in three out of five cases.

Saling (1966) considers that the pHqu40 provides a more meaningful index of the condition of the foetus. On the other hand other workers have suggested that the level of metabolic acidosis has little advantage over the actual $\mathrm{pH}$ in prediction of the condition of infant (Beard et al., 1967; Hon et al., 1969; Khazin, Hon \& Quilligan, 1969). The results in the present study did show that the metabolic component gave a better prediction. Among the cases with pH below 7.20 (groups $\mathrm{X}$ and $\mathrm{Y}$ ), those in group $X$ with depressed infants all had a pHqu40 of below $7 \cdot 20$ and a standard bicarbonate of less than 15 
TABLE 2. Distribution of Apgar scores relative to the $\mathrm{pH}$ of foetal blood samples collected within $30 \mathrm{~min}$ before delivery

\begin{tabular}{|c|c|c|c|c|c|}
\hline \multirow{3}{*}{ Author } & \multirow{3}{*}{$\begin{array}{l}\text { No. of } \\
\text { cases }\end{array}$} & \multirow{2}{*}{\multicolumn{2}{|c|}{$\begin{array}{c}\text { Foetal } \mathrm{pH}>7 \cdot 20 \\
\text { Apgar score }\end{array}$}} & \multirow{2}{*}{\multicolumn{2}{|c|}{$\begin{array}{c}\text { Foetal } \mathrm{pH}<7 \cdot 20 \\
\text { Apgar score }\end{array}$}} \\
\hline & & & & & \\
\hline & & $7-10$ & $1-6$ & $7-10$ & $1-6$ \\
\hline $\begin{array}{l}\text { Beard et al. (1967) } \\
\text { Kubli (1968) } \\
\text { Bowe et al. }(1970) \\
\text { Present series }\end{array}$ & $\begin{array}{r}176 \\
77 \\
355 \\
88\end{array}$ & $\begin{array}{c}101(87 \%) \\
53(90 \%) \\
232(88 \%) \\
76(98 \cdot 7 \%)\end{array}$ & $\begin{array}{c}15(13 \%) \\
6(10 \%) \\
34(12 \%) \\
1(1.3 \%)\end{array}$ & $\begin{array}{l}25(42 \%) \\
10(55 \%) \\
27(30 \%) \\
6(54.5 \%)\end{array}$ & $\begin{array}{c}35(58 \%) \\
8(45 \%) \\
62(70 \%) \\
5(45 \cdot 5 \%)\end{array}$ \\
\hline
\end{tabular}

$\mathrm{mEq} / 1$ whereas for cases in group $\mathrm{Y}$ with vigorous infants, the pHqu40 was over 7.20 and standard bicarbonate more than $15 \mathrm{mEq} / 1$ except in one case. The differences in the mean pHqu40 and standard bicarbonate between group $\mathrm{X}$ and group $\mathrm{Y}$ were in fact statistically significant $(P<0 \cdot 05)$.

Some workers regard any foetal $\mathrm{pH}$ of less than $7 \cdot 25$ as abnormal. Lumley and co-workers (Lumley, McKinnon \& Wood, 1971) consider pH 7.25 as the lower limit of normal. Bretscher \& Saling (1967) consider $\mathrm{pH}$ values between $\mathbf{7 . 2 0}$ and $\mathbf{7 . 2 4}$ as 'preacidosis'. In the present series of eighty-eight cases delivered within $30 \mathrm{~min}$ after sampling there were seventeen with foetal $\mathrm{pH}$ within this range and all the seventeen infants were delivered with an Apgar score of 7 or more. These results tended to agree with those of Galloway (1970).

In fact the present study indicated that the high incidence of false positive results could be attributed to the setting of the critical $\mathrm{pH}$ at too high a level$7 \cdot 20$. The cases in group $\mathrm{Y}$ had $\mathrm{pH}$ higher than $7 \cdot 13$ while the $\mathrm{pH}$ was below $7 \cdot 13$ in all the cases in group $\mathrm{X}$ (Fig. 1). If the critical $\mathrm{pH}$ level had been set at $7 \cdot 13$ the false positive results would have been completely eliminated, and the error of prediction in cases delivered within 30 min of sampling would be reduced from $7 \cdot 9$ to $1 \cdot 1 \%$.

The error in prediction was not significantly influenced by the sampling-delivery interval whether it was $15 \mathrm{~min}, 30 \mathrm{~min}$ or $3 \mathrm{hr}$ (Fig. 2). Had the critical $\mathrm{pH}$ been set at $7 \cdot 13$ there would have been no false positive results and the error of prediction in cases delivered within $3 \mathrm{hr}$ of sampling would te reduced from $9 \cdot 2$ to $4 \cdot 4 \%$ (Fig. 3).

The most significant factor affecting the degree of correlation between the foetal $\mathrm{pH}$ and the Apgar score appears to be the setting of the critical $\mathrm{pH}$ level. In this series of Chinese patients, the closest correlation would have been achieved with a critical $\mathrm{pH}$ of $7 \cdot 13$.

\section{Acknowledgment}

I am grateful to Professor Daphne Chun for encouragement in this work and permission to publish these results.

\section{References}

BEARD, R.W. (1970) Foetal blood sampling. British Journal of Hospital Medicine, 3, 523.

Beard, R.W., Morris, E.D. \& Clayton, S.G. (1966) Foetal blood sampling in clinical obstetrics. Journal of Obstetrics and Gynaecology of the British Commonwealth, 73, 562.

Beard, R.W., Morris, E.D. \& Clayton, S.G. (1967) pH of foetal capillary blood as an indicator of the condition of the foetus. Journal of Obstetrics and Gynaecology of the British Commonwealth, 74, 812.

Bowe, E.T., Beard, R.W., Finster, M., Poppers, P.J., ADAMSONS, K. \& JAMES, L.S. (1970) Reliability of foetal blood sampling, American Journal of Obstetrics and Gynaecology, 107, 219.

BRetsCher, J. \& Saling, E. (1967) pH values in the human fetus during labor. American Journal of Obstetrics and Gynaecology, 97, 906.

GallowaY, R.K. (1970) Clinical experience with foetal blood $\mathrm{pH}$ measurement in foetal distress. Journal of Obstetrics and Gynaecology of the British Commonwealth, 77, 589.

Haworth, S.G., Milic, A.B. \& Adamsons, K. (1968) Biochemical indices of foetal condition, Clinical Obstetric and Gynaecology, 11, 1182.

Hon, E.H., Khazin, A.F. \& Paul, R.H. (1969) Biochemical studies of the foetus. II. Foetal pH and Apgar scores. Obstetrics and Gynaecology, 33, 237.

Khazin, A.F., Hon, E.H. \& Quilligan, E.J. (1969) Biochemical studies of the foetus. III. Foetal base and Apgar scores. Obstetrics and Gynaecology, 34, 592.

Kubl, F. (1966) Fetale Gefahrenzustande und Ihre Diagnose. Geog. Thiem, Stuttgart.

LEE, K.H. (1972a) Acid-Base status of the Chinese foetus during normal labour. Journal of the Asian Federation of Obstetrics and Gynaecology (in press).

LeE, K.H. (1972b) Foetal acid-base status in clinical foetal distress and high risk cases. Postgraduate Medical Journal 48, 91 .

Lumley, J., McKinnon, L. \& Wood, C. (1971) Lack of agreement on normal values for fetal scalp blood. Journal of Obstetrics and Gynaecology of the British Commonwealth $78,13$.

Lumley, J. \& Wood, C. (1969) Foetal acidosis. Australian and New Zealand Journal of Obstetrics and Gynaecology, 9, 145.

Paul, W.M., Gare, D.J. and Whetham, J.C. (1967) Assessment of fetal scalp sampling in labor. American Journal of Obstetrics and Gynaecology, 99, 745.

Saling, E. (1965) A New method of safeguarding the life of the foetus before and during labour. Journal of the International Federation of Gynaecology and Obstetrics, 3, 100.

SAlING, E. (1966) Foetal and Neonatal Hypoxia. Translated by F. E. Loeffler. Edward Arnold, London.

Wood, C., Ferguson, R., Leeton, J., Newman, W. \& WALKER, A. (1967) Fetal heart rate and acid-base status in the assessment of fetal hypoxia. American Journal of Obstetrics and Gynaecology, 98, 62. 